\title{
Role of Thyroid Hormone in Postnatal Circulatory and Metabolic Adjustments
}

\author{
Jeffrey A. Breall, Abraham M. Rudolph, \\ and Michael A. Heymann \\ Cardiovascular Research Institute and the Departments of \\ Pediatrics, Physiology, and Obstetrics, Gynecology, and \\ Reproductive Sciences, University of California, \\ San Francisco, California 94143
}

bstract. To assess the role of the early postnatal surge in plasma thyroid hormone concentrations on cardiovascular and metabolic adaptations, we measured cardiac output, total oxygen consumption, and plasma triiodothyronine (T3) concentrations in three groups of lambs in the first $6 \mathrm{~h}$ after delivery. 15 fetal lambs were prepared at gestational ages of $128-129 \mathrm{~d}$ by placing catheters in the brachiocephalic artery, descending aorta, distal inferior vena cava, left atrium, and pulmonary artery so that measurements could be made soon after delivery. They were divided into three groups: Group I comprised five control animals; Group II consisted of five fetuses in which thyroidectomy was performed at surgery at 129 d gestation; and Group III consisted of five animals in which thyroidectomy was performed at term gestation during delivery by caesarian section, prior to severing the umbilical cord. The lambs in Group I exhibited a rapid postnatal rise in T3 concentrations, similar to that described previously, reaching a peak value of about $5 \mathrm{ng} / \mathrm{ml}$. Although the postnatal surge in T3 concentration was arrested in Group II and III animals, Group II had no detectable plasma T3, while the Group III animals had T3 concentrations of about $0.8 \mathrm{ng} / \mathrm{ml}$, which were within the range previously reported for term lamb fetuses. The lambs in group II showed 40-50\% lower left ventricular outputs (190 vs. $297 \mathrm{ml} / \mathrm{kg}$ per min), systemic blood flows ( $155 \mathrm{vs.} 286 \mathrm{ml} / \mathrm{kg}$ per $\mathrm{min}$ ), and oxygen consumptions (9.8 vs. $20.2 \mathrm{ml} / \mathrm{kg}$ per min) as compared with Group I animals over the entire 6-h period. The

Address all correspondence to Dr. Rudolph, 1403-HSE, University of California, San Francisco, CA 94143.

Received for publication 5 October 1983 and in revised form 12 January 1984.

J. Clin. Invest.

(c) The American Society for Clinical Investigation, Inc.

0021-9738/84/05/1418/07\$1.00

Volume 73, May 1984, 1418-1424 lambs in Group II also had significantly lower heart rates (131 vs. 192 beats/min) and mean systemic arterial pressures (56 vs. 72 torr). However, there were no significant differences for any of these measurements between the Group III and Group I lambs. The reduction in cardiac output in the Group II animals were reflected in a significantly lower blood flow to the peripheral circulation, but there were no significant differences in blood flow to other organs in the three groups. These studies indicate that plasma thyroid concentrations in the 2-3 wk prior to delivery and not the increase in thyroid hormone concentrations which occur after birth are important for postnatal cardiovascular and metabolic adjustments. We speculate that lack of circulating triiodothyronine in late gestation may affect postnatal cardiovascular adaptation by modifying normal beta adrenergic receptor development.

\section{Introduction}

The adaptation from fetal to extrauterine life is associated with major circulatory, respiratory, and metabolic adjustments. The function of gas exchange is transferred from the placenta to the lungs, and this is accomplished by elimination of the umbilicalplacental circulation, increase in pulmonary blood flow, and closure of the ductus arteriosus and foramen ovale. In addition, whereas fetal body temperature is maintained largely by the intrauterine environment, temperature regulation following birth is dependent on metabolism. Oxygen consumption by the body has been measured in fetal lambs in utero and is $\sim 8 \mathrm{ml} / \mathrm{kg}$ per min $(1,2)$, but during the first week after birth, it increases to $15-21 \mathrm{ml} / \mathrm{kg}$ per $\min (3,4)$. We have shown that combined ventricular output in fetal lambs is about $450 \mathrm{ml} / \mathrm{min}$ per $\mathrm{kg}$ body weight, and that the left ventricle ejects about $150 \mathrm{ml} / \mathrm{kg}$ per min $(5,6)$. Postnatally, left ventricular output is greatly increased to $300-425 \mathrm{ml} / \mathrm{kg}$ per min during the first week. The mechanisms responsible for these changes have not been delineated. Many hormonal changes are known to occur after birth, such as increases in plasma catecholamine and thyroid hormone concentrations. It is not known whether the increase in cardiac 
output immediately after birth could result from the rise in catecholamine concentration. The maintained high cardiac output over the first few weeks cannot, however, be accounted for by catecholamine activity because administration of the beta adrenergic receptor blocker, propranolol, did not produce major reductions in cardiac output 5-7 d after birth. In this study, we have examined the relationship of the postnatal increase in plasma thyroid hormone concentrations to the changes in cardiac output and oxygen consumption in newborn lambs.

\section{Methods}

We studied 15 mixed-breed pregnant ewes with known breeding dates. All the animals were of similar gestational age, and five ewes were assigned to each of three groups. Similar surgical procedures and placement of vascular catheters were performed in all the animals, but the three groups differed in regard to whether thyroidectomy was performed and the timing of the thyroidectomy. In Group I animals, the gestational age was $129 \pm 2 \mathrm{~d}$ at the time of surgery, and the thyroid gland was left intact. Group II animals were operated on at $129 \pm 3 \mathrm{~d}$ and total thyroidectomy was performed at that time. Surgery was performed in Group III animals at $128 \pm 3 \mathrm{~d}$; in these animals, the thyroid gland was not disturbed at the time of surgery. 10-14 d later, they were delivered by caesarian section and thyroidectomy was performed prior to clamping and cutting the umbilical cord.

Surgical preparation. Procedures were performed with lower body anesthesia in the ewe, achieved with epidural injection of 2-3 $\mathrm{ml}$ of $1 \%$ tetracaine hydrochloride (Pontocaine). During the procedure, ketamine $\mathrm{HCl}$ (Vetalar) was given intravenously in $100 \mathrm{mg}$ doses intermittently to maintain sedation of the ewe. Polyvinyl catheters were inserted into a maternal pedal artery and vein, and then, with strict aseptic procedures, the uterus was exposed through a midline abdominal incision. Using techniques we have described in detail previously, catheters were inserted into the following fetal vascular sites: hindlimb pedal artery and vein internal thoracic artery, left atrium, and pulmonary trunk (8). All fetal surgical procedures were done after local anesthesia was achieved with $0.25 \%$ lidocaine $\mathrm{HCl}$. Briefly, a hindlimb was exposed through a small uterine incision, and polyvinyl catheters $(1.2 \mathrm{~mm}$ o.d., $0.8 \mathrm{~mm}$ i.d.) were inserted into a pedal artery and vein and advanced to the distal descending aorta and inferior vena cava, respectively. Succinylcholine was administered intravenously to the fetus in a dose of $5 \mu \mathrm{g} / \mathrm{kg}$ estimated weight to facilitate exposure of the chest. A second uterine incision was made over the left chest and a thoracotomy was performed in the fourth intercostal space. A polyvinyl catheter ( $1.2 \mathrm{~mm}$ o.d., $0.8 \mathrm{~mm}$ i.d.) was advanced from the internal thoracic artery to the brachiocephalic trunk. Specially designed catheters were inserted into the left atrium and pulmonary trunk. We have described these catheters for cannulation of the fetal renal vein (9). A short length of the tapered end of a 20 gauge teflon cannula was pressure-fitted into polyvinyl tubing ( $1.2 \mathrm{~mm}$ o.d., $0.8 \mathrm{~mm}$ i.d.); these were replaced over the needle cannula, and the catheter and needle assembly were advanced through the wall of the vessel or chamber. The cannula was removed and the polyvinyl tubing was connected to a length of larger-bore vinyl catheter; it was secured with a single suture at the site of insertion. The fetal chest was closed, and the left atrial, internal thoracic, and pulmonary arterial catheters were filled with heparin solution $(1,000 \mathrm{U} / \mathrm{ml})$, cut to within $10 \mathrm{~cm}$ of their exit from the chest wall, and sealed with copper wire plugs. These catheters were left in the amniotic cavity for use after delivery of the fetus.
In those animals in which thyroidectomy was performed at the time of the first surgical procedure (Group II), the fetal head was exteriorized through the same uterine incision. To avoid possible inhalation of air, additional succinylcholine was administered intravenously to the fetus in a dose of $5 \mathrm{mg}$ just before exposing the head, and the snout was covered with a wet towel. Using local anesthesia, a 3-cm midline incision was made extending from the larynx toward the suprasternal region. The two lobes of the thyroid gland were carefully dissected away from the trachea and the adjacent carotid arteries, and removed completely. Care was also taken to remove the isthmus. The incision was closed, the head returned to the amniotic cavity, and the uterine incision sutured. A polyvinyl catheter was left in the amniotic cavity, and it as well as the hindlimb catheters (maternal and fetal) were exteriorized on the left flank of the ewe where they were protected in a cloth pouch sutured to the skin. On the day of surgery and on the following $5 \mathrm{~d}, 1,000,000 \mathrm{U}$ penicillin $\mathrm{G}$ and $200 \mathrm{mg}$ kanamycin sulfate were injected into the maternal venous catheter and into the amniotic cavity catheter.

Following recovery from the surgery, the ewe was placed in a study cage. Fetal arterial blood gases and $\mathrm{pH}$, and plasma protein concentrations were measured on alternate days. 5-7 d postoperatively, the fetuses in Group II were given $10 \mu \mathrm{g}$ triiodothyronine (3,3',5-triiodo-L-thyronine, sodium salt; Sigma Chemical Co., St. Louis, MO) intravenously. A second similar dose was administered $2 \mathrm{~d}$ later, this was done to attempt to prevent serious hypothyroid complications which had been described in thyroidectomized fetuses. When the fetuses reached 145 -d gestation or when total fetal plasma protein concentration reached a level of 4.5 $\mathrm{g} / \mathrm{dl}$, they were delivered and subjected to further study. In preliminary studies, we had found that when fetuses were delivered at a younger age or with lower plasma protein concentrations, they frequently exhibited serious respiratory difficulty. The use of plasma protein concentration to assess fetal maturation is based on the observations of Bland (10). The fetuses were delivered 14-18 d following surgery; there was no significant difference in the time after surgery that the three groups were delivered.

Study following delivery. When delivery of the fetus was planned, low epidural anesthesia was accomplished again. An anterior abdominal incision was made to the right of the midline to expose the uterus. An incision was made over the head and the fetus was extracted, but care was taken to avoid twisting or compressing the umbilical cord. The trachea was intubated with a cuffed tube through the mouth and tracheal fluid was allowed to drain. A $3 \mathrm{ml}$ blood sample was withdrawn from the femoral arterial catheter. The left atrial, pulmonary arterial, and brachiocephalic catheters were cleared of heparin and connected to needles and stopcocks. In the Group III animals, under local anesthesia to the neck, a total thyroidectomy was performed as described above. The umbilical cord was then ligated and cut, and the lamb was transferred to a prepared study area where it was placed on its right side on a warming pad. Temperature was monitored continuously. The lamb was covered and a warming lamp was also positioned over the animal to maintain constant temperature. If respiratory activity was not well established, the lamb was ventilated with a Harvard respiratory pump (Harvard Apparatus Co., Inc., South Natick, MA) to maintain normal blood gases and $\mathrm{pH}$ (see Table I). The catheters were connected to Statham P23Db pressure transducers (Gould, Inc., Statham Instruments Division, Oxnard, CA) for continuous recording of vascular pressures on a Beckman direct writing oscillograph (Beckman Instruments, Inc., Fullerton, CA). All pressures were referred to zero level at the midchest position. Heart rate was recorded continuously by a tachometer triggered by the arterial pressure pulse.

Oxygen consumption was measured continuously using the technique 
Table I.

\begin{tabular}{lccc}
\hline & $\begin{array}{l}\text { Group I } \\
(n=5)\end{array}$ & $\begin{array}{l}\text { Group II } \\
(n=5)\end{array}$ & $\begin{array}{l}\text { Group III } \\
(n=4)\end{array}$ \\
\hline Fetal pH & $7.38 \pm 0.04$ & $7.37 \pm 0.04$ & $7.37 \pm 0.04$ \\
Fetal $\mathrm{PO}_{2}$ (torr) & $20 \pm 3$ & $19 \pm 2$ & $19 \pm 3$ \\
Fetal $\mathrm{PCO}_{2}$ (torr) & $48 \pm 4$ & $49 \pm 3$ & $49 \pm 4$ \\
Weight $(k g)$ & $3.48 \pm 0.70$ & $3.95 \pm 0.71$ & $3.42 \pm 0.77$ \\
Neonatal pH & $7.38 \pm 0.06$ & $7.40 \pm 0.08$ & $7.42 \pm 0.08$ \\
Neonatal $\mathrm{PO}_{2}$ (torr) & $63 \pm 7$ & $57 \pm 8$ & $63 \pm 4$ \\
Neonatal $\mathrm{PCO}_{2}$ (torr) & $35 \pm 4$ & $33 \pm 5$ & $31 \pm 4$ \\
& & & \\
\hline
\end{tabular}

The fetal descending aortic $\mathrm{pH}, \mathrm{PO}_{2}$, and $\mathrm{PCO}_{2}$ measured $24 \mathrm{~h}$ prior to delivery did not differ in the three groups of lambs. Also, the mean blood gases and $\mathrm{pH}$, measured over the 6-h period of postnatal study, did not differ in the three groups.

we described previously $(3,4)$. Briefly, a hood was placed over the lamb's head and a constant volume of air was withdrawn through the hood. The air and expired gas were withdrawn through a mixing chamber. The fraction of oxygen in the air mixture was measured with a Servomex oxygen analyzer (Servomex Controls Ltd., Crowborough, Sussex, Great Britain) and recorded on a strip chart recorder. When the lamb was ventilated, the air was withdrawn from around the expiratory outlet of the respiratory pump. The first two lambs studied in Group I were allowed to breathe spontaneously for the first hour or two after delivery, but because arterial $\mathrm{PCO}_{2}$ began to rise, ventilation was assisted. The remaining animals in Group I and all animals in Groups II and III were ventilated from delivery and throughout the study period.

Using local anesthesia, the right external jugular vein was exposed through a small incision in the neck, and a \#4F balloon-tip directed Swan-Ganz catheter (Edward Lab, Santa Ana, CA) was inserted and advanced to the right ventricle guided by pressure monitoring. Blood samples were collected for measurement of systemic arterial blood gases and $\mathrm{pH}$, plasma triiodothyronine (T3) ${ }^{\prime}$ concentration, and oxygen saturation and hemoglobin concentration. Oxygen saturation was also measured in pulmonary arterial, right ventricular, and left atrial blood. These blood samples enabled us to confirm the absence of right-to-left shunt through the ductus arteriosus and to detect the presence of leftto-right shunts through the ductus; only small left-to-right shunts were present in some animals. The calculation of blood flows by the Fick method were made at $1.5 \mathrm{~h}$ after delivery and every hour thereafter for $6 \mathrm{~h}$ more.

Left ventricular output and its distribution were measured by the radionuclide-labeled microsphere method. $15-\mu \mathrm{m}$ diameter microspheres labeled with one of the following gamma emitters, ${ }^{153} \mathrm{Gd},{ }^{57} \mathrm{Co},{ }^{114 \mathrm{~m}} \mathrm{In}$, ${ }^{51} \mathrm{Cr},{ }^{113} \mathrm{Sn},{ }^{85} \mathrm{Sr},{ }^{95} \mathrm{Nb},{ }^{54} \mathrm{Mn}$, or ${ }^{65} \mathrm{Zn}$, were injected into the left atrium, while reference blood samples were withdrawn from the brachiocephalic and descending aortic catheters for $1.5 \mathrm{~min}$ at a rate of $7 \mathrm{ml} / \mathrm{min}$ with a Harvard constant withdrawal pump (Harvard Apparatus Co., Inc.). The microsphere studies were performed $1 \mathrm{~h}$ after delivery and then each hour after this up to $6 \mathrm{~h}$ after delivery. After each study, the volume of blood removed was replaced with heparinized fetal blood that had been collected from the umbilical cord and placenta after delivery. In the latter two or three studies, if adequate amounts of fetal blood were not available, maternal blood was administered.

1. Abbreviations used in this paper: $\mathrm{T} 3$, plasma triiodothyronine.
At the end of the procedure, the lamb was killed with an overdose of intravenous sodium pentobarbital. The dissection of organs was carried out as previously described. Individual organs and tissues were incinerated and counted for radioactivity in a computerized multichannel pulse height analyzer. The quantitation of individual radionuclides in each tissue, and calculation of left ventricular output and organ blood flows were performed with the Nova 3 computer on line with the analyzer as described previously (11).

Measurements. Oxygen saturation and hemoglobin concentration were measured with a Radiometer OSM2 hemoximeter. Oxygen contents were determined from oxygen capacity, calculated by multiplying hemoglobin concentration by 1.35 , and oxygen saturation. Blood gases and $\mathrm{pH}$ were measured on a DSM2 hemoximeter (Radiometer, Copenhagen, Denmark) or Corning 175 blood gas analyzer. Total T3 concentrations were measured by radioimmunoassay (T3 RIA Kit, Corning Medical and Scientific, Medfield, MA). The lower limit of the assay was $0.25 \mathrm{ng} / \mathrm{ml}$. Each sample was run in duplicate and there was an intraassay variation of $18 \%$. The inter-assay variation was $12 \%$.

Analysis. Left ventricular output, systemic blood flow, mean arterial blood pressure, heart rate, and blood flows to various organs were analyzed and compared among the three groups on an hourly basis during the first $6 \mathrm{~h}$ after delivery using a repeated measures two-way analysis of variance. The Newman-Keuls multiple comparisons test was employed to examine statistical differences among the three groups. A difference was considered to be statistically significant at $P<0.05$. Mean values over the first $6 \mathrm{~h}$ were obtained for $\mathrm{pH}, \mathrm{PO}_{2}$, and $\mathrm{PCO}_{2}$, and these values were compared among the three groups using a simple one-way analysis of variance and the Newman-Keuls multiple comparison test. Fetal blood gases and $\mathrm{pH}$ were obtained $24 \mathrm{~h}$ prior to delivery and fetal weight was measured at the end of the study. These features were compared using the same statistical methods.

\section{Results}

The fetuses in the three groups developed normally and there were no significant differences in $\mathrm{pH}, \mathrm{PO}_{2}$, and $\mathrm{PCO}_{2}$ in descending aortic blood measured $24 \mathrm{~h}$ prior to delivery (Table I). There were also no significant differences in body weights of the three groups of animals on the day of delivery. The mean blood gas and $\mathrm{pH}$ values over the 6-h period of study after birth are shown in Table I as well, and these also did not differ in the three groups.

Total plasma T3 concentrations measured immediately before clamping the umbilical cord (hour 0 ) and for the first $6 \mathrm{~h}$ after delivery are shown in Fig. 1. Groups I and III had identical $\mathrm{T} 3$ concentrations of $0.8 \mathrm{ng} / \mathrm{ml}$ prior to cord clamping, whereas there was no detectable T3 in Group II animals. However, plasma T3 concentrations were significantly different between each group at hours 1-6 $(P<0.001)$. After delivery, the Group II animals continued to have undetectable $\mathrm{T} 3$ concentrations throughout the $6 \mathrm{~h}$. However, the animals in Group I showed a marked increase in plasma $\mathrm{T} 3$ concentrations, similar to the pattern described before for normal lambs after birth $(12,13)$.

Left ventricular outputs were similar at each hourly period after delivery in the Group I and Group III animals (Fig. 2). However, left ventricular outputs of Group II animals were significantly lower than those of either Group I or Group III 


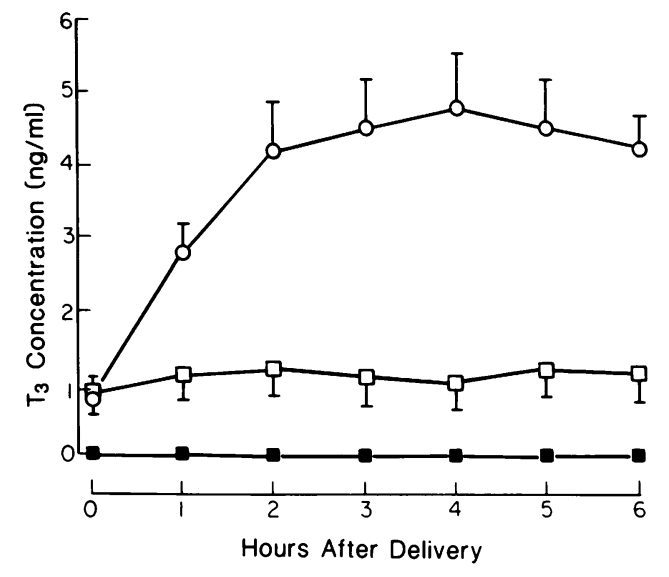

Figure 1. The changes in T3 concentrations are shown in the three groups of lambs. Group I animals $(O)$ were controls. Group II animals ( $\square$ ) were thyroidectomized during fetal life. Group III animals $(\square)$ were thyroidectomized at the time of delivery (mean $\pm S D$ ).

animals at each period $(P<0.005)$. Left ventricular output also did not change significantly in any of the three groups over the 6-h period after delivery.

Because left ventricular output after birth reflects both systemic blood flow and whatever blood may be shunted left-toright through a patent ductus arteriosus, we calculated systemic blood flow from the radionuclide-labeled microsphere injection, as well as by the Fick method. We confirmed, as we have reported previously (14), that there was no significant difference in the values obtained by the two methods. Left ventricular output was not significantly different between groups I and III, but was markedly lower in group II $(P<0.001)$. There was also no change with time after delivery in any of the groups.

Heart rates and mean arterial pressures were also significantly lower in Group II animals as compared with Groups I and III

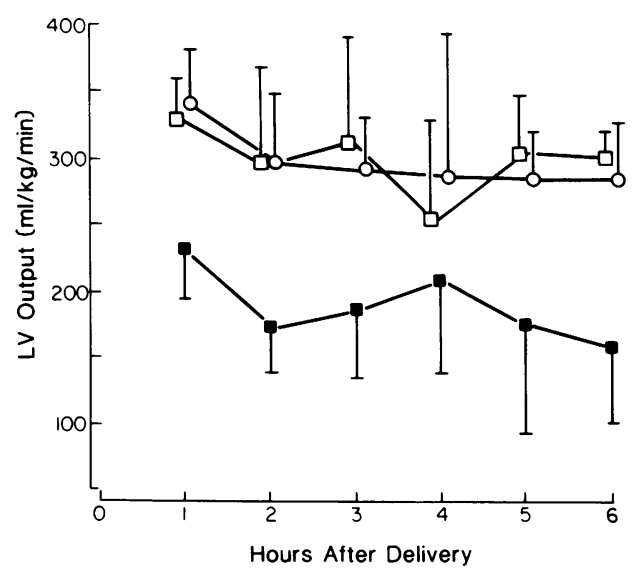

Figure 2. Changes in left ventricular (LV) output are shown for the animals in Group I (O), Group II ( $\square$ ), and Group III ( $\square$ ) $($ mean \pm SD). animals $(P<0.001)$, and the latter two groups did not differ significantly. There was also no significant change of heart rate or arterial blood pressure over the 6-h observation period (Figs. 3 and 4).

Oxygen consumptions were significantly lower in the Group II animals as compared with those in Group I and III ( $P$ $<0.001)$. There were no significant differences between Group I and III, and no significant changes occurred over the 6-h observation period (Fig. 5).

Organ blood flows were calculated from the radionuclidelabeled microsphere injections. The Group II animals showed a significantly lower blood flow (in relation to tissue weight) to the peripheral circulation, which represents skin, muscle, subcutaneous tissue, bone, and fat, as compared with both Groups I and III $(P<0.05)$. Also, blood flow to the gut was lower in Group II as compared with Group III $(P<0.05)$, but not with Group I. Apart from these differences, blood flows to all other organs (milliliters per 100 grams per minute) were not significantly different in the three groups, although there was a trend toward somewhat lower flows to all organs in Group II animals.

Blood flow to the lungs, as measured by the microsphere technique, represents bronchial flow as well as blood shunted left-to-right through the ductus arteriosus and microspheres which have passed through the peripheral circulation. The calculated flow (milliliters per 100 grams per minute) did not differ significantly in the three groups, indicating that there was no significant difference in ductus left-to-right shunt in the thyroidectomized animals. In all the animals, $<12 \%$ of microspheres injected into the left ventricle appeared in the lungs, indicating that in the first hour after delivery, the ductus arteriosus was almost completely closed functionally.

\section{Discussion}

During fetal life, there is admixture of oxygenated blood returning from the placenta with venous blood from the fetal body. Blood distributed to the lungs and to various fetal organs

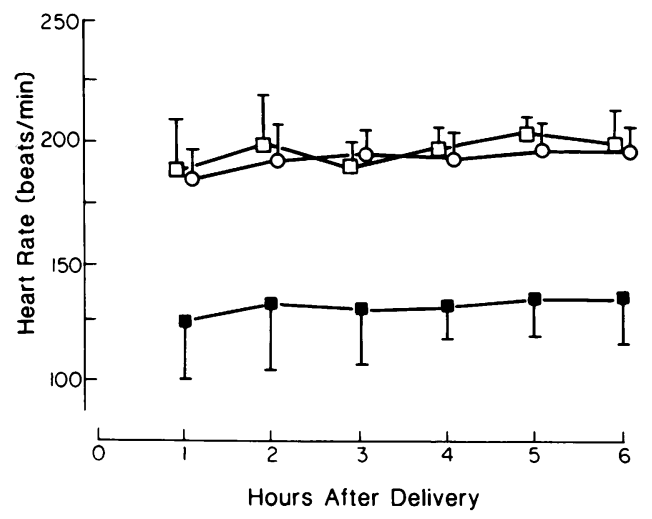

Figure 3. Heart rates are shown at various times after delivery in Group I (O), Group II ( $\square$ ), and Group III ( $\square$ ) animals (mean \pm SD). 


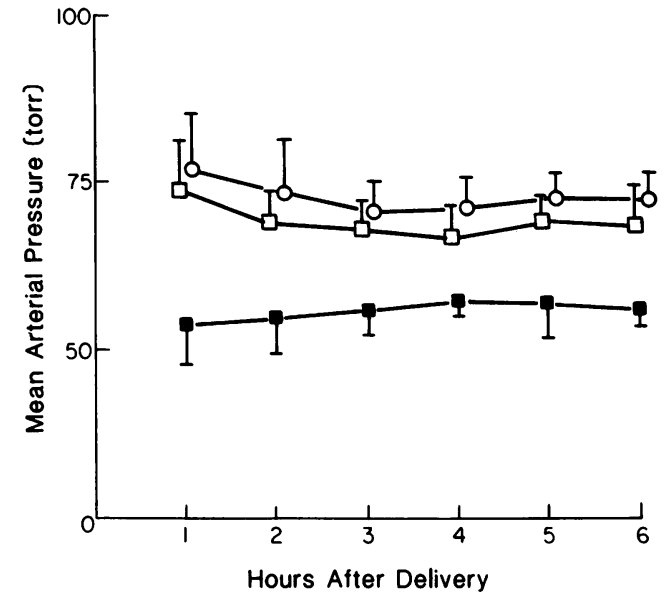

Figure 4. Mean arterial blood pressure are shown in the Group I (O), Group II ( $\square$ ), and Group III ( $\square$ ) lambs (mean \pm SD).

and to the placenta is derived from umbilical and systemic venous return. In fetal lambs in utero, the combined output of the two ventricles is about $450-500 \mathrm{ml} / \mathrm{kg}$ per $\mathrm{min}$; the right ventricle ejects about $300 \mathrm{ml} / \mathrm{min}$ per $\mathrm{kg}$ fetal body weight, whereas the left ventricle ejects only about $150 \mathrm{ml} / \mathrm{kg}$ per min (6). Studies with blood volume adjustments to alter preload on the fetal ventricles suggest that under normal conditions, the fetal heart functions near the peak of its function curve. We found that right ventricular output increased only by 15-20\% when saline was infused intravenously to increase right ventricular end-diastolic pressure to as much as $25 \mathrm{mmHg}$ (15). Gilbert showed that when atrial pressure was reduced below its resting level of $\sim 3 \mathrm{mmHg}$, combined ventricular output fell dramatically, but increasing pressure produced only a $15-20 \%$ rise with pressures to about 5-6 $\mathrm{mmHg}$ with no further increase as atrial pressure was raised beyond these levels (16). Whether this limitation in increase of ventricular output in response to a rise of ventricular pressure is due to low compliance of the ventricle, as has been shown by Romero et al. (17), or to limited intrinsic contractility of fetal cardiac muscle, or to a combination of both factors, has not yet clearly been delineated.

After birth, the circulation assumes the series circuit characteristic of the adult. Cardiac output is now designated as the output of each ventricle, and during the first week after birth, has been shown to be $300-425 \mathrm{ml} / \mathrm{kg}$ per $\min (3,4)$. Thus, left ventricular output increases by two- to almost threefold after birth, whereas during fetal life it shows a limited response to volume loading. The factors responsible for the change in ventricular performance have not been defined. Also, it is not known whether the change occurs in very late prenatal life or some time after birth because there are no sequential observations of cardiac output immediately before and after birth. In this study, we have shown that, within an hour after delivery, left ventricular output has already increased to the high levels reported during the first week. It is still possible, however, that the ability for the ventricles to markedly increase output has occurred within a few days prior to delivery.

Plasma catecholamine concentrations increase immediately after birth (18), and it is possible that this is important in promoting the rise in cardiac output immediately after birth. However, catecholamines do not appear to be solely responsible for maintaining the increased cardiac output, because administration of propranolol to block beta adrenergic receptors decreased resting heart rate and left ventricular output in 1-wk-old lambs by only 12 and $15 \%$, respectively (7).

The possibility that the postnatal increase in cardiac output could be related to thyroid activity was entertained because plasma thyroid-stimulating hormone as well as T3 and T4 concentrations have been shown to increase dramatically after birth. Serum thyroid-stimulated hormone concentrations increase within $30 \mathrm{~min}$, and $\mathrm{T} 3$ concentrations increase immediately and within several hours have risen three- to sixfold $(12,13)$. We have clearly demonstrated that in lambs thyroidectomized before birth, T3 is not detectable in fetal plasma and there is no increase in concentrations after delivery. In these lambs, cardiac output was considerably lower than in nonthyroidectomized lambs, as were heart rate and arterial blood pressure.

Increased plasma thyroid hormone concentrations are associated with increased myocardial contractility $(19,20,21)$. There are several possible mechanisms that have to be considered. It has been suggested by some investigators that thyroid hormone has a direct effect on the myocardium (22) but this has been disputed (23). In a review of the mechanism of the inotropic effects of thyroid hormone, it was suggested that it was largely dependent on altered cardiac myosin ATPase activity (24). Fink and Morkin (25) indicated that the increased contractility of the hyperthyroid heart could at least in part be accounted for by appearance of a new species of myosin with a greater actin-activated ATPase activity. Another possible

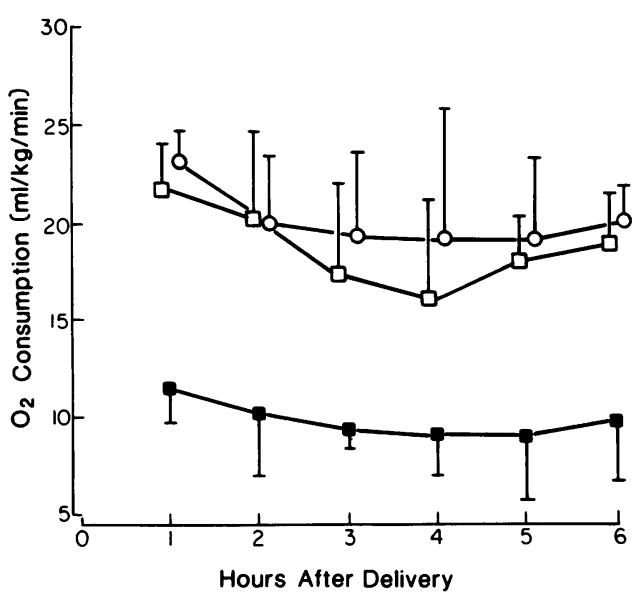

Figure 5. The oxygen consumption values for lambs in Group I (O), Group II ( $\square$ ), and Group III ( $\square$ ) are shown at various periods after delivery $($ mean $\pm \mathrm{SD})$. 
mechanism by which thyroid hormone may increase myocardial contractility is through its effect on $\mathrm{Na}^{+}, \mathrm{K}^{+}$-ATPase activity; administration of $\mathrm{T} 3$ to hypothyroid rats increased cardiac $\mathrm{K}^{+}$ and reduced $\mathrm{Na}^{+}$, an effect which correlated with the enzyme activity (26). It has also been proposed that thyroid hormone may possibly regulate energy conservation in mitochondria (27) and Nishiki et al. (28) showed that both cytochrome and mitochondrial proteins were increased in hyperthyroid rat hearts in relation to wet weight. Others have proposed that thyroid hormones may indirectly influence myocardial performance through the sympathetico-adrenal system. It does not appear that thyroid hormones increase catecholamine secretion nor that they directly increase myocardial sensitivity to catecholamines $(29,30)$. Several studies have indicated that excess thyroid hormones increase the number of myocardial beta adrenergic receptors $(31,32)$. Furthermore, myocardial beta adrenergic receptors are greatly reduced in developing rat pups made hypothyroid in utero (33). Although it is possible that the postnatal increase in plasma $\mathrm{T} 3$ concentrations could increase myocardial beta adrenergic receptor numbers and thereby facilitate myocardial response to the increased circulating catecholamine concentrations, we felt that the rise in cardiac output occurred too soon after delivery to be explained by these changes. Therefore, we studied a third group of animals (Group III) and showed that if the thyroid gland was removed immediately prior to delivery, cardiac output rose normally after birth, and the low heart rate and blood pressure observed after delivery in the animals thyroidectomized earlier in gestation were not evident. In the lambs thyroidectomized just prior to delivery, plasma $\mathrm{T} 3$ concentrations were similar to those observed late in gestation in normal lambs, but no postnatal increase in T3 concentrations occurred. It is thus apparent that the postnatal cardiovascular adaptations are dependent on normal prenatal thyroid function and not on the postnatal increase in thyroid activity.

Thyroid activity increases progressively during late gestation, but within a few days prior to birth, there is a marked increase in plasma T3 concentrations to levels similar to those we recorded immediately prior to delivery in Groups I and III animals. It is possible that the late prenatal rise in plasma $\mathrm{T} 3$ concentrations increases myocardial beta adrenergic receptor numbers or responsiveness, so that there is greater myocardial response to sympathetico-adrenal stimulation. Our previous observation that propranolol, a beta adrenergic blocker, does not greatly reduce resting cardiac output in newborn lambs (7) would suggest that increased beta adrenergic receptor sensitivity is not an important mechanism for the increased cardiac output. However, these studies were performed in lambs 5-7 d after birth. It is still possible that this mechanism is important in the immediate postnatal period. However, other possible mechanisms of action include effects of $\mathrm{T} 3$ on cardiac myosin ATPase and $\mathrm{Na}^{+}, \mathrm{K}^{+}-$ ATPase, as mentioned above. Thyroid has been reported to increase myocardial mass by inducing hypertrophy (34) and this could influence the heart's ability to increase cardiac output. However, the hypertrophy could be secondary to the increased work to which the heart is subjected. In our study, there was no significant difference in myocardial weight in Group I and Group II animals, so that this could not have accounted for the differences in left ventricular output.

Postnatally, normal lambs demonstrate an increase in oxygen consumption concomitant with the rise in cardiac output. We have previously reported that there are parallel changes in cardiac output and oxygen consumption after birth (4) and suggested that changes in metabolism and oxygen consumption determine changes in cardiac output. Oxygen consumption of the fetuses thyroidectomized in utero was quite low, but in those thyroidectomized immediately prior to delivery, oxygen consumption was similar to that in the control animals. It is possible, therefore, that the low cardiac output in the lambs thyroidectomized in late gestation is secondary to the low oxygen consumption. However, because hypothyroidism has been shown to affect beta adrenergic receptor numbers, it is interesting to speculate that both the low oxygen consumption and the low cardiac output could be the result of reduced beta adrenergic receptor response in brown fat and the myocardium, respectively.

The low cardiac output observed in the thyroidectomized animals did not appear to have any major effect on organ function. Blood supply to all organs was not significantly reduced, but the main reduction of blood flow was to the peripheral circulation. We did not assess, however, whether this was due to reduced flow to skin, muscle, or brown fat.

\section{Acknowledgments}

The invaluable technical assistance of Ms. Christine Roman, Mr. Bruce Payne, and Mr. Ronald Bayreuther is gratefully acknowledged.

This work was supported by grants from the U. S. Public Health Service: Program Project grant HL24056, and HL23681.

\section{References}

1. Boyd, R. D., F. H. Morriss, Jr., G. Meschia, E. L. Makowski, and F. C. Battaglia. 1973. Growth of glucose and oxygen uptakes by fetuses of fed and starved ewes. Am. J. Physiol. 225:897-902.

2. Battaglia, F. C., and G. Meschia. 1978. Principal substrates of fetal metabolism. Physiol. Rev. 58:499-529.

3. Sidi, D., J. R. G. Kuipers, M. A. Heymann, and A. M. Rudolph. 1983. Effects of ambient temperature on oxygen consumption and the circulation in newborn lambs at rest and during hypoxemia. Pediatr. Res. 17:254-258.

4. Lister, G., T. K. Walter, P. R. Dallman, and A. M. Rudolph. 1979. Oxygen delivery in lambs; cardiovascular and hematologic development. Am. J. Physiol. 237:H668-H675.

5. Rudolph, A. M., and M. A. Heymann. 1970. Circulatory changes during growth in the fetal lamb. Circ. Res. 26:289-299.

6. Heymann, M. A., R. K. Creasy, and A. M. Rudolph. 1973. Quantitation of blood flow patterns in the foetal lamb in utero. In Proceedings of the Sir Joseph Barcroft Centenary Symposium: Foetal and Neonatal Physiology. Cambridge University Press, Cambridge. 129-135.

7. Klopfenstein, H. S., and A. M. Rudolph. 1978. Postnatal changes in the circulation and responses to volume loading in the sheep. Circ. Res. 42:839-845. 
8. Rudolph, A. M., and M. A. Heymann. 1980. Methods for studying the circulation of the fetus in utero. In Animal Models in Fetal Medicine. P. W. Nathanielsz, editor. Elsevier/North-Holland Biomedical Press, Amsterdam. 1-37.

9. Iwamoto, H. S., and A. M. Rudolph. 1983. Chronic renal venous catheterization in fetal sheep. Am. J. Physiol. 245:H524-H527.

10. Bland, R. D. 1972. Cord-blood total protein level as a screening aid for the idiopathic respiratory-distress syndrome. N. Engl. J. Med. 287:9-12.

11. Baer, R. W., B. Payne, E. D. Verrier, G. J. Vlahakes, D. Molodowitch, P. N. Uhlig, and J. I. E. Hoffman. 1984. Increased number of myocardial blood flow measurements with radionuclide-labelled microspheres. Am. J. Physiol. 246:H418-H434.

12. Nathanielsz, P. W., M. Silver, and R. S. Comline. 1973. Plasma triiodothyronine concentration in the foetal and newborn lamb. J. Endocrinol. 58:683-684.

13. Fisher, D. A., J. H. Dussault, J. Sack, and I. J. Chopra. 1977. Ontogenesis of hypothalamic-pituitary-thyroid function and metabolism in man, sheep, and rat. Recent Prog. Horm. Res. 33:59-166.

14. Kuipers, J. R. G., D. Sidi, M. A. Heymann, and A. M. Rudolph. 1982. Comparison of methods of measuring cardiac output in newborn lambs. Pediatr. Res. 16:594-598.

15. Heymann, M. A., and A. M. Rudolph. 1973. Effects of increasing preload on right ventricular output in fetal lambs in utero. Circulation. 48:IV-37.

16. Gilbert, R. D. 1980. Control of fetal cardiac output during changes in blood volume. Am. J. Physiol. 238:H80-H86.

17. Romero, T., J. Covell, and W. F. Friedman. 1972. A comparison of pressure-volume relations of the fetal, newborn, and adult heart. Am. J. Physiol. 222:1285.

18. Padbury, J. F., E. S. Diakomanolis, C. J. Hobel, A. Perelman, and D. A. Fisher. 1981. Neonatal adaptation: sympatho-adrenal response to umbilical cord cutting. Pediatr. Res. 15:1483-1487.

19. Buccino, R. A., J. F. Spann, Jr., P. E. Pool, E. H. Sonnenblick, and $E$. Braunwald. 1967. Influence of thyroid state on the intrinsic contractile properties and energy stores of the myocardium. J. Clin. Invest. 46:1669-1682.

20. Skelton, C. L., H. N. Coleman III, K. Wildenthal, and E. Braunwald. 1970. Augmentation of myocardial oxygen consumption in hyperthyroid cats. Circ. Res. 27:301-309.
21. Taylor, R. R., J. W. Covell, and J. J. Ross. 1969. Incidence of the thyroid state on left ventricular tension-velocity relations in the intact sedated dog. J. Clin. Invest. 48:775-784.

22. Levey, G. S., and S. E. Epstein. 1969. Myocardial adenyl cyclase. Activation by thyroid hormones and evidence for two adenyl cyclase systems. J. Clin. Invest. 48:1663-1669.

23. Skelton, C. L., F. E. Karch, and K. Wildenthal. 1973. Lack of acute effects of thyroid hormones on myocardial contractility. Am. J. Physiol. 224:957.

24. Morkin, E. 1979. Stimulation of cardiac myosin adenosine triphosphatase in thyrotoxicosis. Circ. Res. 44:1-7.

25. Fink, I. L., and E. Morkin. 1977. Evidence for a new cardiac myosin species in thyrotoxic rabbits FEBS (Fed. Eur. Biochem. Soc.) Letter. 81:391-394.

26. Philipson, K. D., and I. S. Edelman. 1977. Thyroid hormone control of $\mathrm{Na}^{+}, \mathrm{K}^{+}$-ATPase and $\mathrm{K}^{+}$-dependent phosphatase in rat heart. Am. J. Physiol. 232:C196-C206.

27. Werner, S. C., and J. Nauman. 1968. The thyroid. Annu. Rev. Physiol. 30:213-244.

28. Nishiki, K., M. Erecinska, D. F. Wilson, and S. Cooper. 1978. Evolution of oxidative phosphorylation in hearts from euthyroid, hypothyroid, and hyperthyroid rats. Am. J. Physiol. 235:C212-C219.

29. Margolius, H. S., and T. E. Gaffney. 1965. Effects of injected norepinephrine and sympathetic nerve stimulation in hyperthyroid dogs. J. Pharmacol. Exp. Ther. 149:329-335.

30. Van der Schoot, J. B., and N. C. Moran. 1964. An experimental evaluation of the reputed influence of thyroxine on the cardiovascular effects of catecholamines. J. Pharmacol. Exp. Ther. 149:336-345.

31. Williams, L. T., R. J. Lefkowitz, S. M. Watanabe, D. R. Hathaway, and H. R. Besch. 1977. Thyroid hormone regulation of $\beta$-adrenergic receptor number. J. Biol. Chem. 252:2787-2789.

32. Whitsett, J. A., A. Noguchi, and J. J. Moore. 1982. Developmental aspects of alpha- and $\beta$-adrenergic receptors. Semin. Perinatol. (NY). 6:125-141.

33. Whitsett, J. A., J. Pollinger, and S. Matz. 1982. $\beta$-adrenergic receptors and catecholamine sensitive adenylate cyclase in developing rat ventricular myocardium: effect of thyroid status. Pediatr. Res. 16:463469.

34. Sandler, G., and G. M. Wilson. 1959. The production of cardiac hypertrophy by thyroxine in the rat. Quart. J. Exp. Physiol. Cogn. Med. Sci. 41:282-289. 